\title{
Pseudoaneurysm Endovascular Treatment of a Middle Colic Arterial Branch in a Patient with an Intermittent Digestive Hemorrhage from an Obscure Source: Case Report
}

Roberto Teodoro Beck¹, Milton Sérgio Bohatch Júnior², Gabriel Ribeiro Perotoni³, Ronald Caputo Júnior ${ }^{4}$, Amanda Fernandes Vidal da Silva ${ }^{2}$ and Marcelo Haddad Dantas ${ }^{1}$

${ }^{1}$ Institute of Angiology Vascular and Endovascular Surgery, Joinville, Santa Catarina, Brazi

${ }^{2}$ General Surgery, Municipal São José Hospital, Joinville, Santa Catarina, Brazil

${ }^{3}$ Vale do Itajaí University, Joinville, Santa Catarina, Brazil

${ }^{4}$ Radiology Department, Hospital Dona Helena, Joinville, Santa Catarina, Brazil

\begin{abstract}
Aneurysms of the middle colic arterial branches are extremely rare, the main manifestation occurs due to the rupture and intraabdominal bleeding making death possible in up to $70 \%$ of cases. Herein, we report a case of a male patient, who is 50 years old and displays intermittent, recurrent, and self-limited episodes of a digestive hemorrhage that has been symptomatic during the course of a three-month investigation. After an extensive investigation, the patient was submitted to angiography detecting a pseudoaneurysm in the middle colic branch, being treated by embolization using micro-coils. Intermittent digestive hemorrhages from an obscure source can represent a diagnostic challenge, due to the high degree of clinical suspicion for performing the correct differential diagnosis. Arteriography must not be delayed whenever a pseudoaneurysm with active bleeding is suspected, as this exam is selected for diagnosis and the preferred method for conclusive treatment.
\end{abstract}

Keywords: Middle colic arterial branches; Angiography; Pseudoaneurysm; Laparoscopic surgery.

\section{Introduction}

Aneurysms are defined whenever the width of an artery is dilated more than 1.5 times its normal size and then they can be classified as true aneurysms and false aneurysms (pseudoaneurysms). Visceral Artery Aneurysms (VAAs) are rare with an estimated incidence ranging from $0.01 \%$ to $2 \%$ in autopsies and angiographic series [1]. Aneurysms can affect any of the abdominal aorta branches, although hepatic and splenic aneurysms represent $80 \%$ of the reported cases. Aneurysms of the superior mesenteric branches are extremely rare especially in the middle colic arterial branches [2,3].

The majority of VAAs tend to expand and eventually rupture, resulting in a potentially fatal situation [3]. The traditional strategies for managing VAAs are to be followed up by performing open surgical imaging or intervention exams. The classic surgical options include ligatures of the aneurysm with or without organ resection (for example, splenectomy) or aneurysmatic resection with revascularization [3].

Through the development of new techniques of minimally invasive intervention and the increased experience of endovascular surgeons, traditional treatment concepts have changed [4]. Herein, we describe a rare case of pseudoaneurysm of the middle colic artery branch responsible for the intermittent digestive hemorrhage condition from an obscure source, diagnosed and successively treated by endovascular technique.

\section{Case Report}

This report is on a male patient, 50 years old, who has a history of arterial hypertension and underwent a bariatric video laparoscopic surgery in 2009 (Fobi-Capella Technique) and who has lost $40 \mathrm{~kg}$ in the past 6 years. An investigation for anemia has been performed since January 2016, when complaints of asthenia and melena were intercalated between normal appearance feces, 3 red blood concentrates were needed in February for symptomatic anemia. One colonoscopy in February displayed only diverticular disease. In March 2016, he was admitted to an emergency room due a history of bright red bleeding in feces, asthenia, and lipothymia for 3 days. He denied abdominal pain, fever, or hematemesis. His vital signs displayed 100 $\times 70 \mathrm{mmHg}$ arterial pressure, a $126 \mathrm{bpm}$ heartbeat, and the absence of fever. The physical exam confirmed mucocutaneous pallor, there was no abdominal pain or visceromegaly. The results from the hospital admission lab examinations were: $5.4 \mathrm{~g} / \mathrm{dL}$ hemoglobin and $15 \%$ hematocrit, $1.09 \mathrm{INR}$, and $28 \mathrm{~s}$ aPTT. The patient was administered $2 \mathrm{red}$ blood concentrates and an investigation for the digestive hemorrhage was carried out by performing a new colonoscopy confirming melena in the ileus and diverticular disease. The upper digestive endoscopy did not show any signs of bleeding. The tagged red blood cell scintigraphy verified the probable source of a bleeding site in the small intestines. The enteroscopy did not show any signs of bleeding, however in the validity period previous to the exam, the patient had not experienced any previous digestive bleeding for 1 week and not all intestinal segments were analyzed due to a previous surgery (gastric bypass, biliary bypass, and excluded stomach).

Due to the persistence of decreasing red blood cell count indexes and the need for frequent blood transfusions, an exploratory laparoscopy was chosen with a laparoscopic gastrostomy

*Corresponding author: Milton Sérgio Bohatch Júnior, Medical Resident (General Surgery), Municipal São José Hospital, Joinville, Santa Catarina, Brazil, Tel: 5547999433299; E-mail: milton.jr87@hotmail.com

Received December 04, 2017; Accepted December 21, 2017; Published December 27, 2017

Citation:Beck RT, Bohatch Júnior MS, Perotoni GR, Júnior RC, da Silva AFV, et al. (2017) Pseudoaneurysm Endovascular Treatment of a Middle Colic Arterial Branch in a Patient with an Intermittent Digestive Hemorrhage from an Obscure Source: Case Report. J Vasc Med Surg 5: 352. doi: 10.4172/2329-6925.1000352

Copyright: (c) 2017 Beck RT, et al. This is an open-access article distributed under the terms of the Creative Commons Attribution License, which permits unrestricted use, distribution, and reproduction in any medium, provided the original author and source are credited. 
Citation: Beck RT, Bohatch Júnior MS, Perotoni GR, Júnior RC, da Silva AFV, et al. (2017) Pseudoaneurysm Endovascular Treatment of a Middle Colic Arterial Branch in a Patient with an Intermittent Digestive Hemorrhage from an Obscure Source: Case Report. J Vasc Med Surg 5: 352. doi:10.4172/2329-6925.1000352

Page 2 of 4

and intraoperative endoscopy to evaluate the excluded stomach and the proximal biliary bypass. However, bleeding was not confirmed during the procedure. Computed Tomography (CT) of the abdomen (Figure 1) performed before, during and after the use of intravenous contrast revealed a hypodensity lesion at pancreas neck posterior margin that was apparently a complex cyst although its precise definition was difficult. An abdominal Nuclear Magnetic Ressonance (MRI) done for diagnostic improvement (Figure 2) showed an oval shaped lesion with $\mathrm{T} 1$ hypointensity and T2 hyperintensity, with minimal peripheral contrast enhancement and measuring around $15 \times 11 \mathrm{~mm}$ at axial plane, compromising the posterior pancreas neck border, rising the possibilities of inflamatory psudocyt, peripancreatyc cistic adenopathy and primary cystic neoplasm.

After 4 days without exteriorizing bleeding, as well as stable hematimetric indexes, new melena episodes occurred with a significant drop in hemoglobin levels to $4.8 \mathrm{~g} / \mathrm{dL}$ and hematocrit $12 \%$. After performing clinical stabilization measures, the patient was submitted to exploratory laparotomy with an intra-operatory enteroscopy without any sign of a bleeding site. The evolution relieved pain, achieved laboratorial stabilization, and stopped digestive bleeding. After 7 days, a new episode of digestive hemorrhage occurred; thereafter it was submitted to arteriography. A puncture provided access to the right femoral artery, utilizing a $6 \mathrm{~F}$ introducer. A pseudoaneurysm was

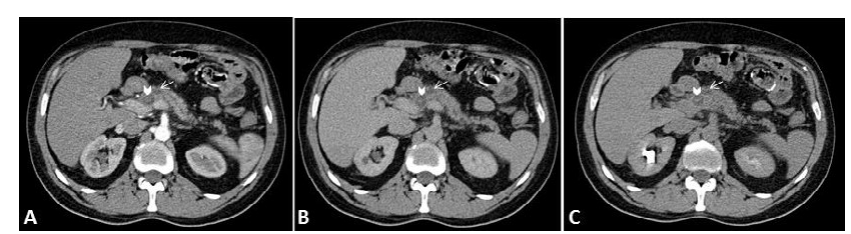

Figure 1: Abdominal CT scan with IV contrast. Arterial phase (A), venous phase (B) and late phase (C) showing a hipodense image at the pancreatic neck (arrowhead) whith discrete contrast enhancement, more evident during the late phase. Wirsung duct (arrow).

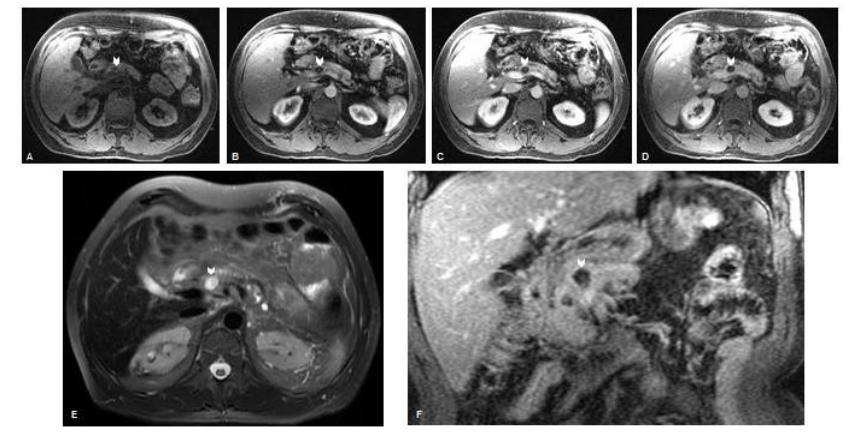

Figure 2: Abdominal MRI: Axial T1 fat sat pre contrast (A), arterial phase (B), venous phase (C) and late phase (D) showing an oval shape hypointensity image with minimal peripheral contrast enhancement at the posterior pancreas neck margin (arrowhead). Axial T2 fat sat image (E) shows lesion hyperintesity (arrowhead). Coronal T1 po contrast fat sat (F) showing lesion (arrowhead) minimal peripheral contrast enhancement. uncovered in the middle colic branch in the selective upper mesenteric arteriography using a micro-catheter (Figure 3A). No contrast overflow was observed during the procedure. The pseudoaneurysm treatment was performed using eleven micro-coils. The arteriography confirmed the pseudoaneurysm was completely excluded and the distal bed of the middle colic artery remained with collateral perfusion (Figure 3B).

There was optimal evolution, received medical release after the $3^{\text {rd }}$ post-operatory. In the follow-up one month after the intervention, no new bleeding episodes occurred and the control angiotomography demonstrated the presence of radiopaque material from the embolization in the pancreaticoduodenal region, forming a rounded image measuring $15 \times 15 \mathrm{~mm}$ and there were no evidences of overflow from the contrast medium (Figure 4).

\section{Discussion}

Aneurysms of the middle colic artery and its branches are extremely rare and represent less than $3 \%$ of aneurysms of visceral arteries [5,6]. The majority of the series report an average age of 60 years old and an approximately equal distribution between genders [5-7].

There are 3 layers of vessels in true aneurysms (endothelium, muscularis and adventitia), the most common etiology is aterosclerose $[2,8]$ and the symptoms are present in 70 to $90 \%$ of cases [2]. False aneurysms or pseudoaneurysms are defined as missing complete arterial walls lined by adventitia or perivascular tissue and arises from the weakening of the arterial wall caused by trauma, including surgical trauma [9], or by proteolytic action as occurs in pancreatitis cases. Because of that, almost all cases of pseudoaneurysms are symptomatic and display greater risk of rupturing than true aneurysms [1,2].

The pathogenesis of bleeding is probably related to intermittent erosion and the wall destruction of the aneurysm due to contact with

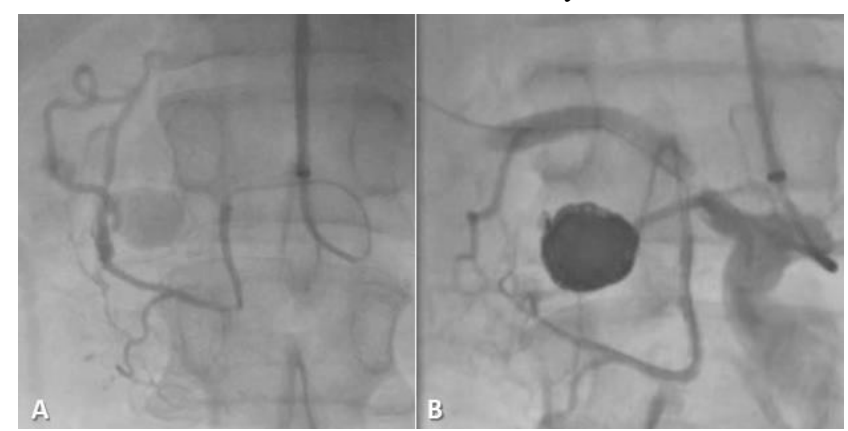

Figure 3: Angiography with iodine contrast: (A) Pseudoaneurysm image (B) Pseudoaneurysm embolization with coils.

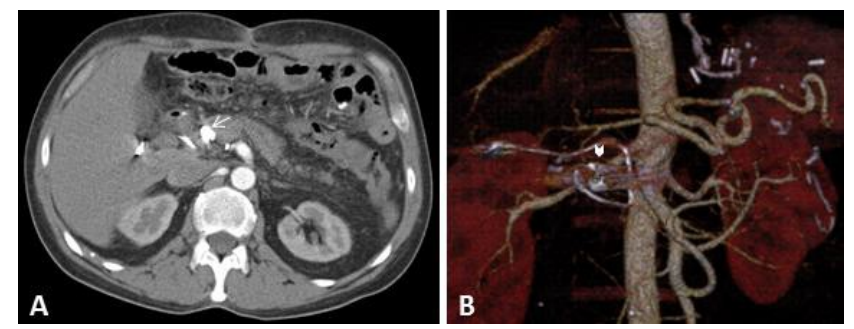

Figure 4: After treatment CTA shows the coils placement at the lesion site in axial (A) and $3 \mathrm{D}$ reconstruction $(\mathrm{B})$ images. 
Citation: Beck RT, Bohatch Júnior MS, Perotoni GR, Júnior RC, da Silva AFV, et al. (2017) Pseudoaneurysm Endovascular Treatment of a Middle Colic Arterial Branch in a Patient with an Intermittent Digestive Hemorrhage from an Obscure Source: Case Report. J Vasc Med Surg 5: 352. doi:10.4172/2329-6925.1000352

Page 3 of 4

the duodenal wall, common bile duct, pseudocyst, or the Wirsung duct, secondary to the pressure necrosis caused by the expanding pseudoaneurysm [10,11]. The image studies of the present case demonstrated intimate contact with the pancreas and the Wirsung duct, simulating pancreatic lesion and even causing, ductal dilatation.

The diagnosis is rarely performed in asymptomatic patients, as it is frequent in those who manifest complications from aneurysms, especially rupturing, present in $90 \%$ of cases. In case of rupturing, the gastrointestinal hemorrhage is the most common clinical manifestation $[11,12]$. It can cause hematemesis, hemobilia, retroperitoneal hemorrhage, and hemorrhagic shock depending on the location [10,11], once it is broken, mortality can reach up to $70 \%$ [2]. An aneurysm of a middle colic artery can display intermittent or slow hemorrhage that lasts for several months [5,6], as the clinical condition is manifested in this case.

Ultrasonography can reveal a hypoechoic cystic lesion strictly related to an artery. Doppler can display the typical entrance and leaving of blood described as a whirlwind movement in a bag through a neck ("yin-yang" sign) [11]. The contrasted computerized tomography can show the aneurysm itself, or identify areas where there is bleeding hiding the aneurysm. We have shown the atypical appearance of a pseudoaneurysm, as it is not detected by contrast. The angiotomography supplies additional information on the pseudoaneurysm, as well as the disease process [11]. The angiography is the gold standard for the diagnosis of pseudoaneurysms due to its capacity to evaluate in real time the location of an overflow. The anatomy of collateral vessels and the extension of affected vessels can be evaluated through this method $[5,11,13]$. The angiography is most sensitive $(100 \%)$, followed by tomography $(67 \%)$ and ultrasound $(50 \%)[11,12]$.

Thus, a high degree of clinical and radiological suspicion is necessary in the interpretation of complementary exams in order to avoid wrong diagnoses. Since, the middle colic artery emerges from the upper mesenteric artery near the head of the pancreas to irrigate the transverse colon and occasionally the hepatic flexure of the colon [14], aneurysmatic dilations can be confused with pseudocysts, adenopathies, and even neoplasms involving the pancreas, as observed in this study. It is probable there will be episodes of pseudoaneurysm ruptures with bleeding to the Wirsung duct and the exteriorization of the digestive hemorrhage, followed by thrombosis, and periods of remission from the symptoms, thereby hindering and even confusing the diagnosis.

In the past, watchful waiting conduct was adopted, followed by ultrasonography, or the patients were then submitted to open surgery. In the last 20 years, due to advances in endovascular techniques, a new modality of treatment has arisen, as an alternative for open surgery, providing the advantage of reducing inherent morbidity and mortality of the procedure [1].

According to guidelines, the treatment of a true visceral aneurysm is recommended when its diameter is $>2 \mathrm{~cm}$ or three times larger than the respective normal artery $[11,15]$. The treatment is also recommended in cases of rapid expansion $>0.5 \mathrm{~cm} /$ year, symptoms, pregnant women, or those who are fertile, and patients submitted to hepatic transplant $[11,14,16]$. Conversely, pseudoaneurysms must be immediately treated as the rupture rate is much greater than true aneurysms $(76.3 \%$ versus $3.1 \%)[11,17]$.

Endovascular management is safe and effective, including fewer complications, shorter hospital stay and recovery $[4,18,19]$. There are various methods for endovascular treatment, including the placement of coils, stent implantation, injection of polyvinyl alcohol particles, gelfoam or glue, and endoluminal thrombin injection $[4,20,21]$. Complications from these procedures are related to femoral cannulation, visceral infarction, abscess, organ necrosis, inadvertent and incorrect occlusion of a vessel, coil migration to other branches, infection or aneurysmatic rupture during embolization [9]. None of these complications have been observed in our work.

Treatment techniques used for each aneurysm must be individualized. Coil embolization is the most commonly utilized, especially in cases when the permeability of vessels is not imperious. There are various different options available for coil embolization, and their use depends on vascular anatomy and the aneurysm [22]. The less invasive endovascular interventions must be priorities in the treatment of visceral aneurysms and pseudoaneurysms. As in case of any failure, there is the possibility of surgical rescue [11].

\section{Conclusion}

Visceral pseudoaneurysms must be considered among the diagnostic hypotheses in patients with a history of surgical manipulation or abdominal trauma and who have developed a digestive hemorrhage from an obscure source. Typical images of aneurysms may not be present when the symptomatology is intermittent, as they can confuse the diagnosis and delay treatment. Arteriography must not be delayed whenever a pseudoaneurysm is suspected accompanied by active bleeding, as that exam must be selected for the diagnosis and it is the chosen method for conclusive treatment.

\section{References}

1. Regus S, Lang W (2016) Rupture Risk and Etiology of Visceral Artery Aneurysms and Pseudoaneurysms: A Single-Center Experience. Vascular and Endovascular Surgery 50: 10-15.

2. Wang AY, Lin TH, Liu KL, Wang HP, Lien WC (2013) Rupture of middle colic artery pseudoaneurysm. American Journal of Emergency Medicine 31: 5-7.

3. Sasahashi N, Kaneko I, Ohya H, Koumura Y, Unoki T, et al. (2009) Successful coil embolization of ruptured middle colic artery aneurysm: a case report. JJAAM 20: 882-886.

4. Khattak YJ, Alam T, Shoaib RH, Sayani R, Haq T, et al. (2014) Endovascular Embolisation of Visceral Artery Pseudoaneurysms. Radiology Research and Practice 2014: 1-6.

5. Moskowitz R, Rundback J (2014) Middle Colic Artery Branch Aneurysm Presenting as Spontaneous Hemoperitoneum. Annals of Vascular Surgery 28 15-17.

6. Huo CW (2012) Middle Colic Artery Aneurysm: A Case Report and Review of the Literature. Ann Vasc Surg 26: 1-6.

7. Yoo BR, Han HY, Cho YK, Park SJ (2012) Spontaneous Rupture of a Middle Colic Artery Aneurysm Arising From Superior Mesenteric Artery Dissection: Diagnosis by Color Doppler Ultrasonography and CT Angiography. J Clin Ultrasound 40: 255-259.

8. Gehlen JM, Heeren PA, Verhagen PF, Peppelenbosch AG (2011) Visceral artery aneurysms. Vasc Endovascular Surg 45: 681-687.

9. Mege D, Louis G, Berthet B (2013) A Rare Cause of Bleeding after Laparoscopic Sleeve Gastrectomy: Pseudo-Aneurysm of the Gastro-Omental Artery. Acta Chir Belg 113: 460-462.

10. Shawky MS, Tan J, French R (2015) Gastroduodenal artery aneurysm: a case report and concise review of literature. Ann Vasc Dis 8: 331-333.

11. Abdelgabar A, Archambeau O, Maes J, den Brande FV, Cools P, et al. (2017) Visceral artery pseudoaneurysms: two case reports and a review of the literature. Journal of Medical Case Reports 11: 126.

12. Habib N, Hassan S, Abdou R, Torbey E, Alkaied H, et al. (2013) Gastroduodena artery aneurysm, diagnosis, clinical presentation and management: a concise review. Ann Surg Innov Res 7: 4 
Citation: Beck RT, Bohatch Júnior MS, Perotoni GR, Júnior RC, da Silva AFV, et al. (2017) Pseudoaneurysm Endovascular Treatment of a Middle Colic Arterial Branch in a Patient with an Intermittent Digestive Hemorrhage from an Obscure Source: Case Report. J Vasc Med Surg 5: 352. doi:10.4172/2329-6925.1000352

Page 4 of 4

13. Chauhan U, Puri SK, Jain N, Garg L, Kapoor A, et al. (2016) Percutaneous thrombin injection under sonographic guidance for exclusion of noncatheterizable post-pancreatitis pseudoaneurysm of the superior mesenteric artery: a minimally invasive and expeditious treatment option. J Med Ultrason (2001) 43: 295-299.

14. Moritani K, Wada O, Ozawa H, Fujita S, Kotake K (2015) Laparoscopic radical right hemicolectomy for cecal cancer and middle colic artery aneurysm. World Journal of Surgical Oncology 13: 170.

15. Loffroy R, Favelier S, Pottecher P, Genson P, Estivalet L, et al. (2015) Endovascular management of visceral artery aneurysms: When to watch, when to intervene? World J Radiol 7: 143-148.

16. Ferrero E, Viazzo A, Ferri M, Robaldo A, Piazza S, et al. (2011) Management and urgent repair of ruptured visceral artery aneurysms. Ann Vasc Surg 25: 987-911.

17. Pitton MB, Dappa E, Jungmann F, Kloeckner R, Schotten S, et al. (2015) Visceral artery aneurysms: incidence, management, and outcome analysis in a tertiary care center over one decade. Eur Radiol 25: 2004-2014.
18. Belli AM, Markose G, Morgan R (2012) The role of interventional radiology in the management of abdominal visceral artery aneurysms. CardioVascular and Interventional Radiology 35: 234-243.

19. Ding X, Zhu J, Zhu M, Li C, Jian W, et al. (2012) Therapeutic management of hemorrhage from visceral artery pseudoaneurysms after pancreatic surgery. Journal of Gastrointestinal Surgery 15: 1417-1425

20. Spiliopoulos S, Sabharwal T, Karnabatidis D, Brountzos E, Katsanos K, et al. (2012) Endovascular treatment of visceral aneurysms and pseudoaneurysms: long-term outcomes from a multicenter European study. Cardiovascular and Interventional Radiology 35: 1315-1325.

21. Izaki K, Yamaguchi M, Kawasaki R, Okada T, Sugimura K, et al. (2011) N-butyl cyanoacrylate embolization for pseudoaneurysms complicating pancreatitis or pancreatectomy. Journal of Vascular and Interventional Radiology 22: 302-308.

22. Fankhauser GT, Stone WM, Naidu SG, Oderich GS, Ricotta JJ, et al. (2011) The minimally invasive management of visceral artery aneurysms and pseudoaneurysms. J Vasc Surg 53: 966-970. 